\title{
Iridium-Catalyzed Regioselective and Enantioselective Allylation of Trimethylsiloxyfuran
}

\author{
Wenyong Chen and John F. Hartwig ${ }^{\star}$ \\ Department of Chemistry, University of California, Berkeley, California, 94720, United States
}

\section{Abstract}

We report the regioselective and enantioselective allylation of an ester enolate, trimethylsiloxyfuran. This enolate reacts in the 3-position with linear aromatic allylic carbonates or aliphatic allylic benzoates to form the branched substitution products in the presence of a metallacyclic iridium catalyst. This process provides access to synthetically important 3substituted butenolides in enantioenriched form. Stoichiometric reactions of the allyliridium intermediate imply that the trimethylsiloxyfuran is activated by the carboxylate leaving group.

Asymmetric allylic substitution catalyzed by metallacyclic iridium phosphoramidite complexes $\mathbf{1}$ and $\mathbf{2}^{1}$ forms enantioenriched materials from readily available allylic esters and a variety of heteroatom ${ }^{2}$ and carbon $^{3}$ nucleophiles. However, the carbon nucleophiles that undergo this process are mainly stabilized enolates. ${ }^{3 \mathrm{a}-\mathrm{h}}$ Reactions of unstabilized enolates ${ }^{3 \mathrm{i}-\mathrm{k}}$ have been limited to those derived from methyl ketones. Enolates of esters that undergo iridium catalyzed allylic substitutions possess a second electron-withdrawing group (EWG) to stabilize the enolate.

Trimethylsiloxyfuran 3a is an important ester enolate because it can be used to construct butenolides, a motif found in over 13,000 natural products. ${ }^{4} \mathrm{High}$ diastereo- and enantioselectivity has been achieved from the addition of $\mathbf{3 a}$ to carbonyl acceptors with Lewis-acid or organic catalysts. ${ }^{4 a, 5}$ These reactions occurred at C-5 of 3a. Regioselective reactions at C-3 of $\mathbf{3} \mathbf{a}$ to form enantioenriched, 3 -substituted butenolides are rare. ${ }^{6}$

One set of palladium-catalyzed kinetic resolutions of methyl substituted allylic acetate with trimethylsiloxyfuran does occur at C-3 of the nucleophile $\mathbf{3 a}$ (a of Scheme 1). ${ }^{7}$ In this case, the regioselectivity at the electrophile was controlled by the properties of the substrate. The attack at the less hindered end of the allyl unit led to the conjugated product. ${ }^{8,}{ }^{9}$ This origin of regioselectivity restricts the scope of electrophiles that give one major product. Moreover, the reactions occurred with only unsubstituted trimethylsiloxyfuran. Asymmetric reactions with catalysts based on other metals could provide complementary selectivities to these palladium-catalyzed reactions. However, asymmetric allylic substitutions catalyzed by complexes of other metals with ester enolates lacking a second EWG have not been reported.

We report an iridium catalyzed allylic substitution between trimethylsiloxyfuran and prochiral electrophiles to form enantioenriched 3-substituted butenolides with high regioselectivity for the more hindered product (b of Scheme 1), including formation of the

*Corresponding Authorjhartwig@berkeley.edu. ASSOCIATED CONTENT Experimental procedures and characterization data. This material is available free of charge via the Internet at http://pubs.acs.org.

The authors declare no competing financial interest. 
deconjugated product from reactions of cinnamyl carbonates. The process furnishes 3substituted butenolides containing an easily functionalized terminal double bond and various aryl and alkyl groups at the stereogenic center. In addition to providing useful butenolides, this process begins to address the challenge of conducting allylic substitution with ester enolates.

Our initial studies focused on the reaction of trimethylsiloxyfuran 3a with cinnamyl carbonate 4a. Table 1 summarizes the effect of several parameters on this reaction. Reactions catalyzed by complexes $\mathbf{1}$ and $\mathbf{2}$ with $\mathrm{CsF}$ to activate the silyl enolate formed the 3 -allylated product 5a regioselectively. ${ }^{10,11}$ The reaction with catalyst $\mathbf{2}$ occurred in higher yield than the reaction with catalyst 1 (entries 1 and 2). Further assessment of fluoride activators showed that reactions conducted with $\mathrm{ZnF}_{2}$ gave the desired product $\mathbf{5 a}$ in a high $85 \%$ isolated yield with $99 \%$ ee (entry 3 ). The reaction with soluble fluoride salts, such as TBAF and TBAT, gave only trace amounts of the desired product (entries 4 and 5). To our surprise, this reaction also proceeded to completion without any additives, although higher catalyst loadings were needed in this case (entries 6 and 7). This final observation is consistent with studies on stoichiometric reactions of catalytic intermediates in the absence of additives described later in this paper.

The scope of the Ir-catalyzed asymmetric allylation of trimethylsiloxyfuran in the presence of $\mathrm{ZnF}_{2}$ is summarized in Table 2. The reaction of the electron-rich, 4-methoxy cinnamyl carbonate $\mathbf{4 b}$ afforded the desired substitution product in good yield with exceptional enantioselectivity and high regioselectivity. The reactions of electron-poor substrates $\mathbf{4 c - e}$ furnished the corresponding products in high yield with excellent regio- and enantioselectivities, although 3-substituted cinnamyl carbonate $4 \mathbf{e}$ required 2 mol \% catalyst loading for full conversion.

Reactions of aliphatic allylic electrophiles occurred with some changes to the reaction conditions. Propyl-substituted allylic carbonate $\mathbf{4 f}$ gave only $18 \%$ yield of branched product $\mathbf{5 f}$ with a 10:1 ratio of $\mathbf{5 f}$ to linear product $\mathbf{6 f}$ (entry 5). However, the reaction of the corresponding aliphatic allylic benzoate $\mathbf{4 g}$ gave the branched allylation product $\mathbf{5 f}$ in good yield and regioselectivity (10:1) with high enantioselectivity (entry 6) in the presence of 3 mol \% catalyst 2 at $50{ }^{\circ} \mathrm{C}$.

These conditions were suitable for a range of aliphatic benzoates. For example, crotyl substrate $4 \mathrm{~h}$ reacted to give the substitution product in $71 \%$ yield with excellent enantioselectivity (entry 7). Furthermore, the branched product formed selectively, even when the aliphatic substituent was branched at the carbon adjacent to the allyl unit (entry 8). The allylic substitution of dienyl benzoate $\mathbf{4} \mathbf{j}$ with catalyst $\mathbf{2}$ yielded the product as a 1:1 mixture of constitutional isomers (entry 9), but occurred with moderate regioselectivity and high enantioselec-tivity when dibenzo[a,e]cyclooctatetraene (DBCOT) was used as a supporting ligand instead of cyclooctadiene (COD) ${ }^{2}$

The reactions of 3, 4, and 5-methyl trimethylsiloxyfurans (3b-d) revealed the effect of furanyl substituents on the catalytic process. The reaction of 3-methyl trimethylsiloxyfuran $\mathbf{3 b}$ gave two products (Scheme 2). The 5 -substituted linear product $\mathbf{6 j}$ was isolated in $28 \%$ yield and $94 \%$ ee. The 3 -substituted product was obtained as inseparable diastereomers $\mathbf{5 j}$ and $\mathbf{5 j}$ '. Heating the mixture of diastereomers in dichloromethane at $40{ }^{\circ} \mathrm{C}$ for $1 \mathrm{~h}$ led to a single diastereomer $\mathbf{5 j}$ containing adjacent quaternary and tertiary stereogenic centers and linear product $\mathbf{6 j}$. Product $\mathbf{6 j}$ formed by a Cope rearrangement of one of the diastereomers. ${ }^{12}$ Thus, the 3 -substituted product $\mathbf{5} \mathbf{j}$ was ultimately isolated as a single diastereomer in $97 \%$ ee by a one-pot process involving asymmetric allylation and Cope rearrangement (Scheme 2, bottom). ${ }^{13}$ 
The reaction of 4-methyl trimethylsiloxyfuran $3 \mathbf{c}$ with cinnamyl carbonate 4a in the presence of the catalyst ( $S, S, S)-2$ also gave products from allylic substitution (Scheme 3). The reaction of $\mathbf{3 c}$ produced the 3-substituted product in $47 \%$ yield, which consisted of double bond isomers $\mathbf{5} \mathbf{k}$ and $\mathbf{5} \mathbf{k}^{\mathbf{2}}$, and the undesired 5 -substituted product in $38 \%$ yield. We were able to convert isomer $\mathbf{5} \mathbf{k}$ ' to isomer $\mathbf{5 k}$ with a catalytic amount of O-desmethyl quinine under mild conditions. ${ }^{14}$ Thus, the overall process furnished the 3 -substituted product $5 \mathbf{k}$ in $45 \%$ yield with $93 \%$ ee. Likewise, the reaction of 5-methyl trimethylsiloxyfuran 3d gave disubstituted butenolides $\mathbf{5 l}$ in an overall $88 \%$ yield with $6: 1$ diastereoselectivity in $99 \%$ ee after isomerization of the diastereomeric mixture of $\mathbf{5 1}$ ' to isomer $\mathbf{5 l}$ in the presence of O-desmethyl quinine. ${ }^{14}$

The products of these substitutions contained two double bonds that underwent further functionalizations (Scheme 4). For example, the terminal double bond of $\mathbf{5 a}$ underwent cross metathesis with vinyl boronate ${ }^{15}$ in the presence of the Grubbs-Hoveyda $2^{\text {nd }}$ generation catalyst. ${ }^{16}$ The resulting vinyl boro-nate $7 \mathbf{a}$ underwent Suzuki-Miyaura coupling with bromoben-zene or 5-bromo-2-methylpyridine to yield 7b or 7c in the presence of $\mathrm{Pd}(\mathrm{Qphos})$ (crotyl)Cl. Compound $\mathbf{5 g}$ was converted to $\mathbf{7 d}$ by a cross metathesis with styrene catalyzed by Schrock's catalyst. ${ }^{17}$ In addition, the electron deficient double bond in $\mathbf{5 l}$ served as a site for conjugate additions. ${ }^{18} \mathrm{Me}_{2} \mathrm{CuLi}$ reacted with $\mathbf{5 l}$ to furnish product $\mathbf{7 e}$ containing four contiguous stereogenic centers.

Stoichiometric reactions were conducted with the Irallylcomplex ${ }^{19}$ to gain insight into the mode of addition and effect of additives on this addition step. The isolated Ir-allyl complex did not react with 1.5 equiv of trimethylsiloxyfuran in the presence of $\mathrm{ZnF}_{2}$ alone (a of Scheme 5) ${ }^{20}$ However, the iridium complex reacted immediately in the presence of 1.0 equiv of $\mathrm{NBu}_{4} \mathrm{OAc}$ with or without $\mathrm{ZnF}_{2}$ to form the product $\mathbf{5 a}$ in $92 \%$ yield and $99 \%$ ee with the same absolute configuration as the product of the catalytic reaction (b of Scheme 5). This observation implies that the carbonate or benzoate generated in situ in the catalytic reaction activates the siloxyfuran. The $R$ absolute configuration of the product of this stoichiometric reaction suggests that nucleophilic attack occurs at the face anti to the iridium fragment.

To determine if the acetate anion activated the trimethylsiloxyfuran directly or if it reacted with Ir-allyl complex to release an allylic acetate that reacted in a subsequent catalytic process, the reaction of the allyliridium complex with trimethylsiloxyfuran 3a was conducted in the presence of 5.0 equiv of $p$-tolyl allylic acetate (c of Scheme 5). If the acetate anion led to the release of the free allylic acetate, little product from the allyl group on iridium would be observed in the presence of excess of the tolyl-substituted allylic acetate. In the event, the reaction of the Ir-allyl complex in the presence of excess of tolylsubstituted acetate formed phenyl-substituted product $\mathbf{5 a}$ in $92 \%$ yield. (The $p$-tolyl product formed in only $37 \%$ yield based on $p$-tolyl allylic acetate.) This yield of phenyl-substituted product $5 \mathbf{a}$ was the same as that formed in the absence of $p$-tolyl allylic acetate, and the yield of $\mathbf{5 a}$ was much higher than that of $p$-tolyl-substituted product. These observations imply that the trimethylsiloxyfuran reacts directly with the Ir-allyl complex when activated by a carboxylate, not by initial release of an allylic ester.

In summary, we report an iridium-catalyzed asymmetric allylic substitution reaction with a silyl ketene acetal. The reaction between a variety of aromatic and aliphatic allylic carbonates or benzoates and trimethylsiloxyfuran proceeded smoothly to furnish 3substituted butenolides in excellent regio- and enantioselectivity. Moreover, methyl substituted trimethylsiloxyfurans react regioselectively to form enantioenriched products. These allylation products can be converted to an array of organic building blocks by reactions at one or the other of the alkene units of the product. Stoichiometric reactions of 
the allyliridium intermediate imply that the reaction proceeds by anti attack on the coordinated allyl ligand, as reported previously for iridium catalyzed allylic substitution with carbon and heteroatom nucleophiles, ${ }^{19 a}$ but that the siloxyfuran is activated by coordination of the carboxylate leaving group. Further studies to expand the scope of the reaction to encompass additional silyl ketene acetals are underway in this laboratory.

\section{Supplementary Material}

Refer to Web version on PubMed Central for supplementary material.

\section{Acknowledgments}

We thank the NIH (GM-58108) for support of this work, Johnson-Matthey for gifts of [ $\operatorname{Ir}(\mathrm{COD}) \mathrm{Cl}] 2$, and Dr. Klaus Ditrich and BASF for gifts of chiral amines. We thank Dr. Phong V. Pham and Dr. Tyler W. Wilson for helpful discussions.

\section{REFERENCES}

(1) (a). Tosatti P, Nelson A, Marsden SP. Org. Biomol. Chem. 2012; 10:3147. [PubMed: 22407450] (b) Liu W-B, Xia J-B, You S-L. Top. Organomet. Chem. 2012; 38:155.(c) Hartwig JF, Pouy MJ. Top. Organomet. Chem. 2011; 34:169.(d) Hartwig JF, Stanley LM. Acc. Chem. Res. 2010; 43:1461. [PubMed: 20873839] (e) Helmchen, G. Iridium-catalyzed asymmetric allylic substitutions. Wiley-VCH Verlag GmbH \& Co.; KGaA: 2009. p. 211

(2) (a). Stanley LM, Hartwig JF. J. Am. Chem. Soc. 2009; 131:8971. [PubMed: 19480431] (b) Shu C, Leitner A, Hartwig JF. Angew. Chem. Int. Ed. 2004; 43:4797.(c) Ohmura T, Hartwig JF. J. Am. Chem. Soc. 2002; 124:15164. [PubMed: 12487578] (d Seehafer K, Helmchen G. J. Am. Chem. Soc. 2011; 133:2072. [PubMed: 21275067] (e) Lyothier I, Defieber C, Carreira EM. Angew. Chem. Int. Ed. 2006; 45:6204.(f) Shu C, Hartwig JF. Angew. Chem. Int. Ed. 2004; 43:4794.(g) Ueda M, Hartwig JF. Org. Lett. 2010; 12:92. [PubMed: 19954200]

(3) (a). Dübon P, Schelwies M, Helmchen G. Chem.-Eur. J. 2008; 14:6722. [PubMed: 18576413] (b) Schelwies M, Dübon P, Helmchen G. Angew. Chem. Int. Ed. 2006; 45:2466.(c) Förster S, Tverskoy O, Helmchen G. Synlett. 2008:2803.(d) Gnamm C, Förster S, Miller N, Brödner K, Helmchen G. Synlett. 2007:790.(e) Dahnz A, Helmchen G. Synlett. 2006:697.(f) Kanayama T, Yoshida K, Miyabe H, Takemoto Y. Angew. Chem. Int. Ed. 2003; 42:2054.(g) Bartels B, GarciaYebra C, Helmchen G. Eur. J. Org. Chem. 2003:1097.(h) Janssen JP, Helmchen G. Tetrahedron Lett. 1997; 38:8025.(i) Weix DJ, Hartwig JF. J. Am. Chem. Soc. 2007; 129:7720. [PubMed: 17542586] (j) He H, Zheng X-J, Li Y, Dai L-X, You S-L. Org. Lett. 2007; 9:4339. [PubMed: 17854201] (k) Graening T, Hartwig JF. J. Am. Chem. Soc. 2005; 127:17192. [PubMed: 16332060] (1) Polet D, Rathgeb X, Falciola CA, Langlois J-B, El HS, Alexakis A. Chem.--Eur. J. 2009; 15:1205. [PubMed: 19072966] (m) Liu W-B, Zheng C, Zhuo C-X, Dai L-X, You S-L. J. Am. Chem. Soc. 2012; 134:4812. [PubMed: 22309279] (n) Zhuo C-X, Liu W-B, Wu Q-F, You S-L. Chem. Sci. 2012; 3:205.(o) Wu Q-F, He H, Liu W-B, You S-L. J. Am. Chem. Soc. 2010; 132:11418. [PubMed: 20677752]

(4) (a). Brown SP, Goodwin NC, MacMillan DWC. J. Am. Chem. Soc. 2003; 125:1192. [PubMed: 12553821] (b) Carmen Zafra-Polo M, Figadère B, Gallardo T, Tormo J, Cortes D. Phytochemistry. 1998; 48:1087.(c) Kitson RRA, Millemaggi A, Taylor RJK. Angew. Chem. Int. Ed. 2009; 48:9426.

(5) (a). Casiraghi G, Zanardi F, Appendino G, Rassu G. Chem. Rev. 2000; 100:1929. [PubMed: 11749280] (b) Singh RP, Foxman BM, Deng L. J. Am. Chem. Soc. 2010; 132:9558. [PubMed: 20583835] (c) Jiang Y-Q, Shi Y-L, Shi M. J. Am. Chem. Soc. 2008; 130:7202. [PubMed: 18479136] (d) Szlosek M, Figadère B. Angew. Chem. Int. Ed. 2000; 39:1799.

(6). For a substrate controlled example, see: Fujioka H, Matsunaga N, Kitagawa H, Nagatomi Y, Kondo M, Kita Y. Tetrahedron: Asymmetry. 1995; 6:2117.; for a racemic example, see: Boukouvalas J, Loach RP. J. Org. Chem. 2008; 73:8109. [PubMed: 18798671]

(7). Mao B, Ji Y, Fañanás-Mastral M, Caroli G, Meetsma A, Feringa BL. Angew. Chem. Int. Ed. 2012; $51: 3168$ 
(8) (a). Hayashi T, Yamamoto A, Hagihara T. J. Org. Chem. 1986; 51:723.(b) Branchadell V, MorenoMañas M, Pajuelo F, Pleixats R. Organometallics. 1999; 18:4934.

(9). Consistent with this origin of regioselectivity, we found that the palladium catalyzed reaction of cinnamyl acetate with 3a failed to deliver the desired product 5a. Instead, a mixture of 3cinnamyl-2-furanone and $\mathbf{6 a}$ formed in a combined $30 \%$ yield. See supporting information for details.

(10). The regioselectivity for reaction at the butenolide is distinct from several processes forming products from attack at $\mathrm{C}-5$. Selectivities from reactions at $\mathrm{C}-5$ have been rationalized by initial [4+2] cycloadditions with an alkene or carbonyl group. In our case, the siloxyfuran activated by an anionic group is more likely reacting as an enolate, which tends to react with electrophiles at the $\mathrm{C}-3$.

(11) (a). For proposed [4+2] mechanism to rationalize C-5 selectivity, see: Cho C-W, Krische MJ. Angew. Chem. Int. Ed. 2004; 43:6689.; Brown DW, Campbell MM, Taylor AP, Zhang X.-a. Tetrahedron Lett. 1987; 28:985.; for a computational study, see: López CS, Ålvarez R, Vaz B, Faza ON, de Lera ÅR. J. Org. Chem. 2005; 70:3654. [PubMed: 15845003] For a C-3 Aldol reaction of lithium enolate, see $11 \mathrm{~b}$.

(12). For a similar aza-Cope rearrangement, see: Kawatsura M, Tsuji H, Uchida K, Itoh T. Tetrahedron. 2011; 67:7686.

(13). The stereochemistry of $\mathbf{5} \mathbf{j}$ and $\mathbf{6 j}$ was tentatively assigned by analogy to the aza-Cope analogue in ref 12 .

(14). Wu Y, Singh RP, Deng L. J. Am. Chem. Soc. 2011; 133:12458. [PubMed: 21766859]

(15) (a). Nicolaou KC, Li A, Edmonds DJ, Tria GS, Ellery SP. J. Am. Chem. Soc. 2009; 131:16905. [PubMed: 19874023] (b) Njardarson JT, Biswas K, Danishefsky SJ. Chem. Commun. 2002:2759.

(16). Garber SB, Kingsbury JS, Gray BL, Hoveyda AH. J. Am. Chem. Soc. 2000; 122:8168.

(17). Compound 7d was determined to have an $S$ configuration by comparing the optical rotation of this material to a literature value in reference 7.

(18) (a). Perlmutter, P. Conjugate Addition Reactions in Organic Synthesis. Pergamon; Oxford, UK: 1992. (b) Rosso GB, Pilli RA. Tetrahedron Lett. 2006; 47:185.

(19) (a). Madrahimov ST, Markovic D, Hartwig JF. J. Am. Chem. Soc. 2009; 131:7228. [PubMed: 19432473] (b) Raskatov JA, Spiess S, Gnamm C, Broedner K, Rominger F, Helmchen G. Chem.--Eur. J. 2010; 16:6601. [PubMed: 20419716]

(20). To understand the effect of $\mathrm{ZnF}_{2},{ }^{19} \mathrm{~F}$ NMR experiments were conducted. The ${ }^{19} \mathrm{~F}$ NMR spectrum of the catalytic reaction (Table 1, entry 3) contained a peak at $-156.9 \mathrm{ppm}$, which matches the ${ }^{19} \mathrm{~F}$ NMR resonance of TMSF. The same species was found in the mixture of $\mathrm{ZnF}_{2}$ and TMSOAc, but not in the mixture of $\mathrm{ZnF}_{2}$ and trimethylsiloxyfuran. These observations suggest that $\mathrm{ZnF}_{2}$ promotes the allylic substitution reaction by reacting with the trimethylsilylcarbonate formed in the reaction to release the carbonate, which then activates the trimethylsiloxyfuran. 

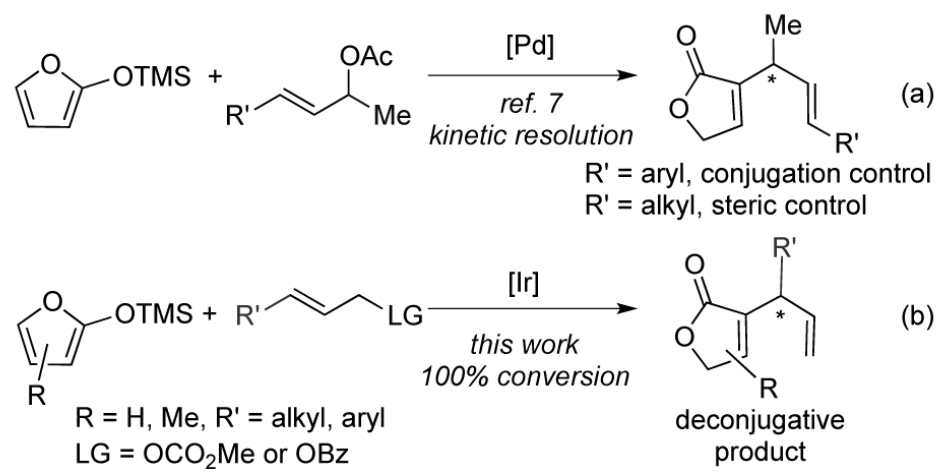
$\mathrm{LG}=\mathrm{OCO}_{2} \mathrm{Me}$ or $\mathrm{OBz}$

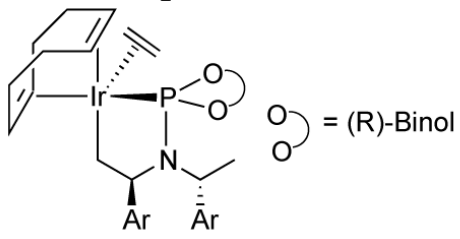<smiles>CC(Br)N(C(C)Br)p1oc2ccc3ccccc3c2c2c(ccc3ccccc32)o1</smiles>

1: $\mathrm{Ar}=\mathrm{Ph}$

2: $\mathrm{Ar}=2-\mathrm{MeO}-\mathrm{C}_{6} \mathrm{H}_{4}$

(Ra, Rc, Rc)-L1: $\mathrm{Ar}=\mathrm{Ph}$

(Ra, Rc, Rc)-L2: $\mathrm{Ar}=2-\mathrm{MeO}-\mathrm{C}_{6} \mathrm{H}_{4}$

SCHEME 1.

Palladium and iridium catalyzed allylic substitution with trimethylsiloxyfuran 

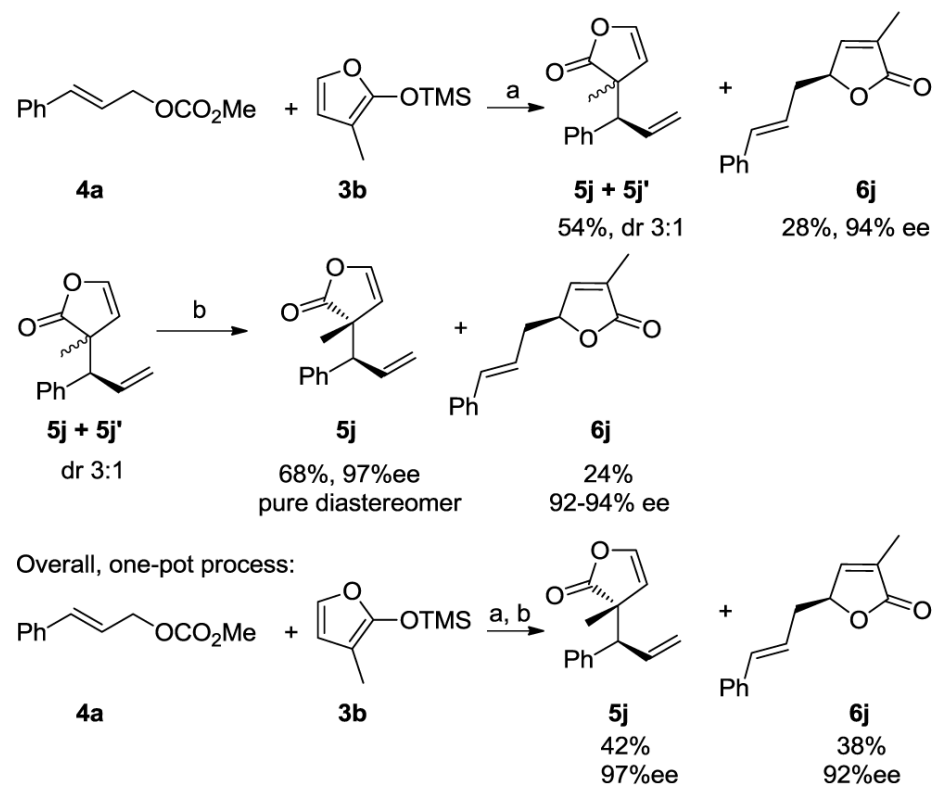

SCHEME 2.

Iridium-catalyzed allylic substitution with 3-methyl substituted trimethylsiloxyfurans ${ }^{\mathrm{a}}$ a (a) $2 \mathrm{~mol} \%(S, S, S)-2, \mathrm{ZnF}_{2}, \mathrm{CH}_{2} \mathrm{Cl}_{2}, 12 \mathrm{~h}$; (b) $40^{\circ} \mathrm{C}, \mathrm{CH}_{2} \mathrm{Cl}_{2}, 1 \mathrm{~h}$ 


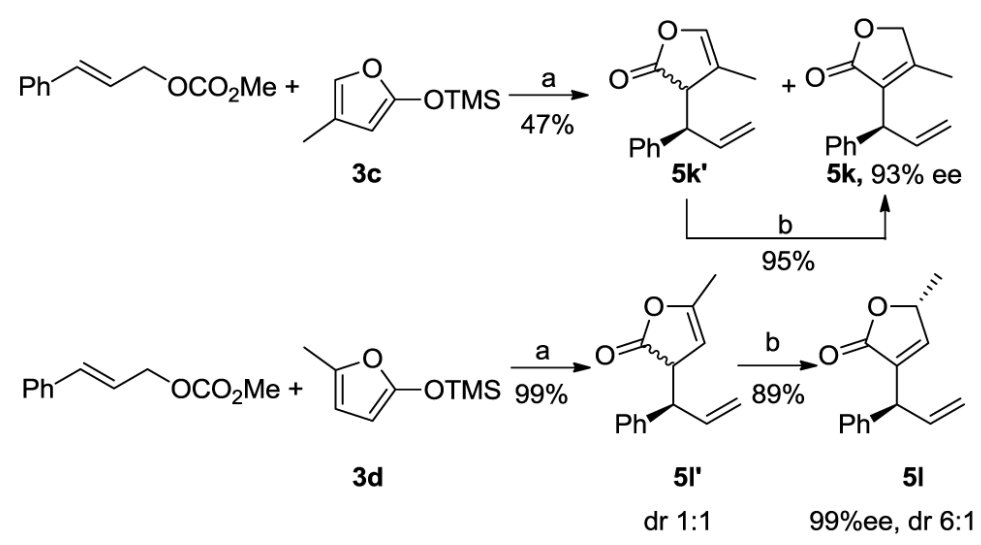

SCHEME 3.

Iridium-catalyzed allylic substitution with 4- and 5-methyl substituted trimethylsiloxyfurans ${ }^{\mathrm{a}}$

a (a) $2 \mathrm{~mol} \%(S, S, S)-2, \mathrm{ZnF}_{2}, \mathrm{CH}_{2} \mathrm{Cl}_{2}, 12 \mathrm{~h}$; (b) 20 mol \% O-desmethyl quinine, $\mathrm{CH}_{2} \mathrm{Cl}_{2}$, $12 \mathrm{~h}$ 

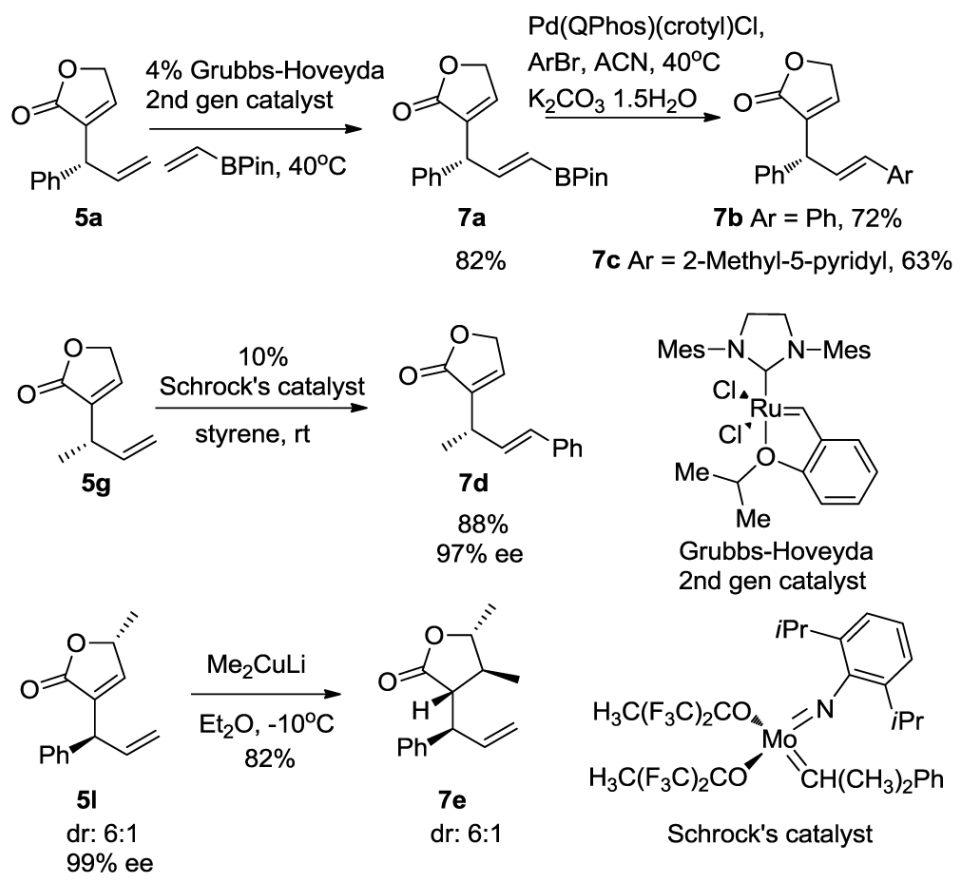

$99 \%$ ee

dr: $6: 1$

Schrock's catalyst

SCHEME 4.

Derivatization of the butenolide product ${ }^{\mathrm{a}}$

a See supporting information for experimental details. All yields reported here are isolated yields. Diastereomeric ratio was determined from ${ }^{1} \mathrm{H}$ NMR spectra of the crude reaction mixtures. ee was determined by chiral HPLC analysis. 


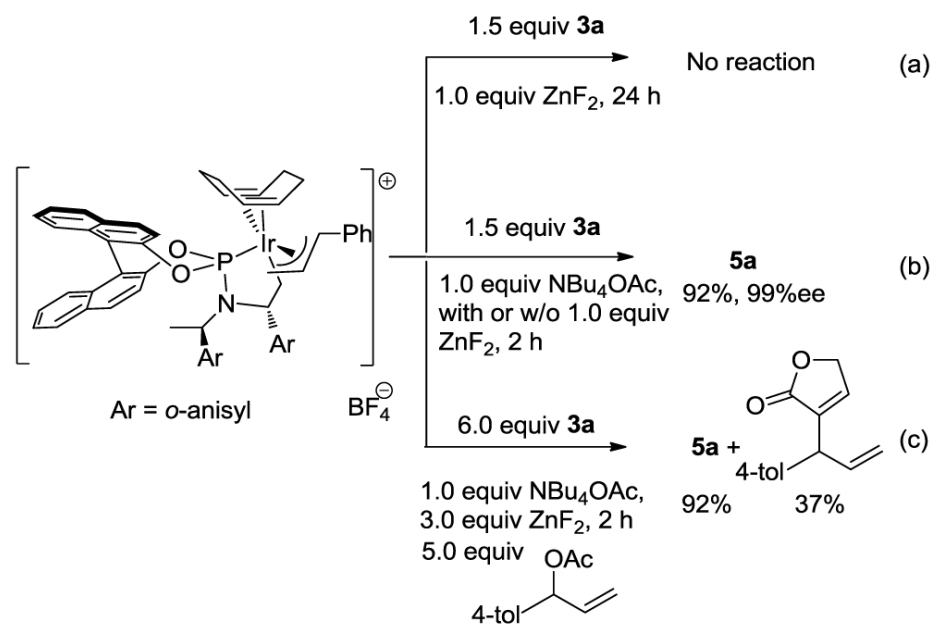

SCHEME 5.

Stoichiometric reactions of the cinnamyl iridium intermediate with trimethylsiloxyfuran 


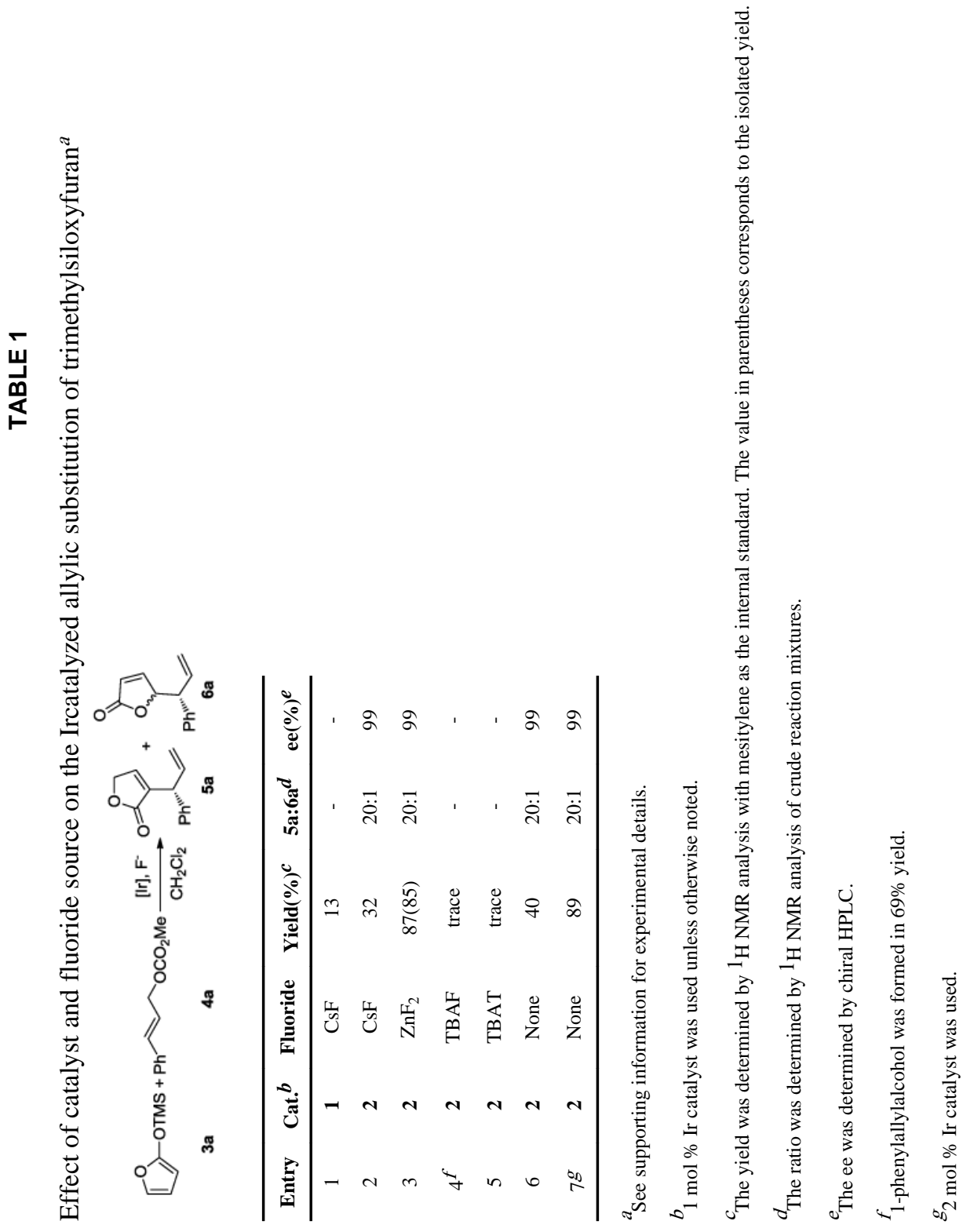

J Am Chem Soc. Author manuscript; available in PMC 2013 September 19. 


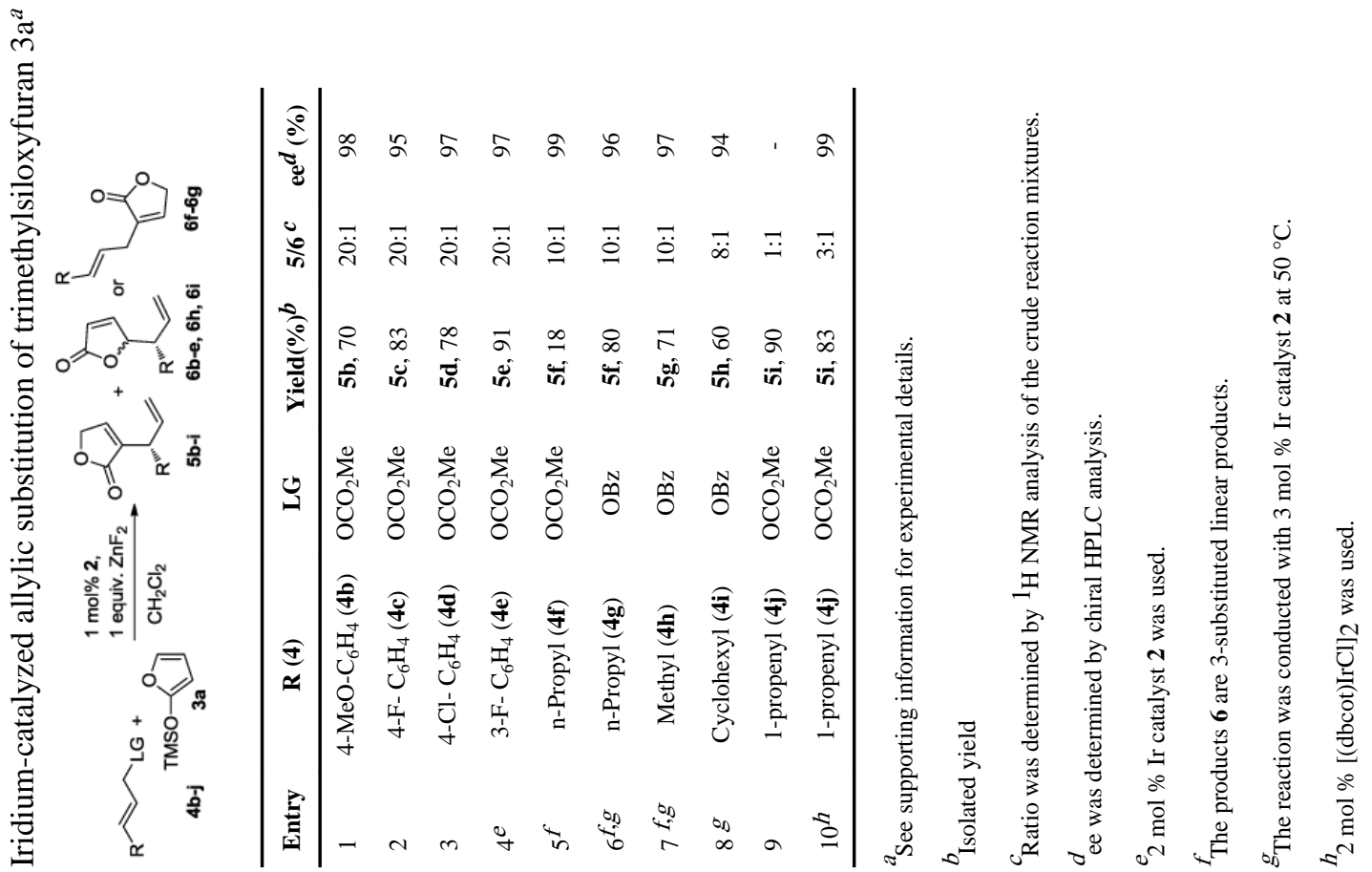

